\title{
Theoretical and Experimental Investigation of the Electronic and Optical Properties of Pure and Interstitial Nitrogen -Doped $\left(\mathrm{TiO}_{2}\right)_{n}$ Cluster
}

Shaida Kakil ( $\square$ shaida.kakil@su.edu.krd)

Salahaddin University - Erbil College of Science https://orcid.org/0000-0003-2635-5849

Hewa Y Abdullah

Tishk International University

Tahseen G. Abdullah

Salahaddin University - Erbil College of Science

\section{Research Article}

Keywords: $\mathrm{N}$ doping, (TiO2)nnanocluster, interstitial, DFT, vibrational mode

Posted Date: November 17th, 2021

DOI: https://doi.org/10.21203/rs.3.rs-975265/v1

License: (c) (i) This work is licensed under a Creative Commons Attribution 4.0 International License. Read Full License 


\section{Abstract}

The structural and electronic properties of pure and nitrogen-doped $\mathrm{TiO}_{2}$ nanoclusters are investigated using density functional theory (DFT) with vibrational modes. We performed numerical simulation using two methods based on theories at the Quantum Espresso/PBE and Gaussian/B3LYP/631G (d) levels. The properties of a single nitrogen-doped $\left(\mathrm{TiO}_{2}\right)_{\mathrm{n}}$ nanocluster are also computed in this study. In both cases, interstitial and substitutional Nitrogen doping at all accessible sites was examined. For the experiment, Supersonic Cluster Beam Deposition (SCBD) was used to create pure and nitrogen-doped $\mathrm{TiO}_{2}$ films of nanocluster assemblies. Atomic force microscopy (AFM), X-ray photoelectron spectroscopy (XPS), UV-Vis spectroscopy, and Raman techniques were used to characterize these samples. The binding energies (Np, $\mathrm{O} 2 \mathrm{~s}, \mathrm{Ti} 2 \mathrm{p} 1 / 2$, and $\mathrm{Ti} 2 \mathrm{p} 3 / 2$ ) of $\mathrm{N}$-doped $\mathrm{TiO}_{2}$ were estimated using XPS spectral results. The UV-Vis measurement confirmed the previously stated reasoning about the quantum size effect on the band gap of the pure and nitrogen doped $\mathrm{TiO}_{2}$ nanocluster. The theoretical vibrational modes frequencies are calculated using the B3LYP/6-31G (d) functional via the Gaussian 16 code's implementation algorithm. The good agreement between simulation and experimental results implies that a significant advantage of interstitial over substitutional positions. $\mathrm{N}-\mathrm{O}$ vibration modes appeared in interstitial doped $\mathrm{TiO}_{2}$, and each vibration was dependent on a different cluster structure.

\section{Introduction}

Nitrogen doped titanium dioxide is gaining popularity due to its potential as a material for environmental photo catalysis. In the last year, numerous theoretical and experimental studies on doped $\mathrm{TiO}_{2}$ have been published. Controlling the size of the nanostructure, on the other hand, is both a problem and a pipe dream for many researchers. The following papers, published in recent years, investigate the physical and chemical properties of $\mathrm{TiO}_{2}$ nanoclusters experimentally and theoretically. I. Shyjumon et al. (Shyjumon et al. 2006) created titanium clusters on a silicon substrate using magnetron sputtering, followed by aggregation in an argon gas flow. Clusters typically range in size from 8 to $13 \mathrm{~nm}$. M. Drabik et al. (Drabik et al. 2011) investigated the design and fabrication of titanium nanocluster films using a magnetronsputtering gas-aggregation cluster source. S. Srivastava et al.(Srivastava et al. 2014) successfully manufactured and collected size-selected $\mathrm{TiO}_{2}$ nanoclusters at room temperature on three distinct substrates: $\mathrm{Si}$, glass, and quartz. They used a special magnetron-sputtering source followed by a quadrupole mass filter. Transmission electron microscopy revealed that NCs larger than a primary size (eight nanometers) have a translucent center with a shapeless shell. M. Chiodi et al.(Chiodi et al. 2012) used Supersonic Cluster Beam Deposition (SCBD) to create co-doped $\mathrm{Cr}-\mathrm{N} \mathrm{TiO}{ }_{2}$ films with significantly improved absorbance in the visible and near infrared. The $\mathrm{Cr}$ and $\mathrm{N}$ dopants are involved in substitution sites. According to the spectroscopic data, the general impact of $\mathrm{N}$ and $\mathrm{Cr}$ substitution co-doping results in the presence of new electronic states at the highest point of the Valence band (VB). Many researchers have reported $\mathrm{TiO}_{2}$ clusters in theory: DFT was used by A. Arab et al., (Arab et al. 2016) to investigate the 
electronic structure and reactivity of $\left(\mathrm{TiO}_{2}\right)_{\mathrm{n}}(\mathrm{n}=1-10)$ nano-clusters. The binding energy per atom, secondorder energy difference, and fragmentation energy were all used to discuss cluster stability.

M. Fronzi et al. (Fronzi et al. 2016) demonstrated the effect of $\mathrm{TiO}_{2}$ nanocluster alteration providing valuable guidelines for further developing $\mathrm{TiO}_{2}$ photo catalytic (UV and visible light) movement, which will be useful for oxidative degradation of organic pollutants or $\mathrm{CO}_{2}$ reduction by utilizing combined DFT recreation and experimentation. The optical absorption spectra of $\left(\mathrm{TiO}_{2}\right)_{n}(\mathrm{n}=1-20)$ nanoclusters and $(\mathrm{n}=$ $35,84)$ nanoparticles have been computationally investigated in gas phase and in water as solvent by $A$. R. Valero et al., (Valero et al. 2018) based on the analysis of the frequency-dependent dielectric function in the independent particle approximation within the framework of the density functional theory. Villanueva et al. (2015)(Salazar-Villanueva et al. 2015) used DFT to investigate the underlying and electronic properties of $\mathrm{Ti}_{9} \mathrm{XO}_{20}(\mathrm{X}=\mathrm{Ti}, \mathrm{C}, \mathrm{Si}, \mathrm{Ge}, \mathrm{Sn}$, and $\mathrm{Pb})$ clusters in order to provide an alternative to experimental strategies for developing new materials with high synergist applications. Kroes and Qu et al. (Qu and Kroes 2006) investigated the electronic structure and steadiness of both nonpartisan and independently charged $\left(\mathrm{TiO}_{2}\right)_{\mathrm{n}}$ groups with $\mathrm{n}=19$ using the DFT with B3LYP/LANL2DZ strategy. The steady construction of $\mathrm{TiO}_{2}$ nanoclusters resulted in a general frame with a minimal design and a couple of $\mathrm{Ti}-\mathrm{O}$ terminal bonds. A few researchers have also theoretically and experimentally focused on the band gap of $\mathrm{TiO}_{2}$ as a function of particle size. S. Monticone et al (Monticone et al. 2000). investigated the $\mathrm{TiO}_{2}$ anatase crystalline phase and discovered that the band gap energy did not vary with size down to $2 \mathrm{R}=1.5 \mathrm{~nm}$. According to UV-vis absorbance measurements, Lin et al.(Lin et al. 2006) believe there is no variation in band gap energy with size. Besides that, they used the MOCVD method to create $\mathrm{TiO}_{2}$ crystalline with varying particle sizes (particle size ranged between 12 and $29 \mathrm{~nm}$ ). The band gap of $\mathrm{TiO}_{2}$ nanoparticles varies with primary particle size. M. Karkare (Karkare 2014) proved that the band gap increased with particle size. With decreasing particle size, the absorption edge shifted to higher energy (blue shift). They demonstrated that a smaller crystallite size $(8.4-10.6 \mathrm{~nm})$ should have a larger band gap of $3.4 \mathrm{eV}$. S. Mandal et al. (Mandal et al. 2019) investigated the optical band gap of these nano composites for pure $\mathrm{TiO}_{2}$, using $3.7 \mathrm{eV}$ as a reference.

In this study, Ab initio calculations are performed and electronic properties for pure $\mathrm{N}$-doped $\mathrm{TiO}_{2}$ are investigated in order to assess the change in properties with respect to the $\mathrm{N}$ content. The formation energies of pure and $\mathrm{N}$-doped $\mathrm{TiO}_{2}$ were computed using two different DFT models: Quantum Espresso/PBE and Gaussian/B3LYP/6-31G (d). The results were analyzed and compared to the experimental. Based on these theoretical observations, pure and $\mathrm{N}$-doped $\mathrm{TiO}_{2}$ samples synthesized using Supersonic Cluster Beam Deposition (SCBD) were characterized, with particular emphasis on the analysis of particle size by AFM (Stylus profilometer KLA Tencor P6), band gap energy values obtained by UV-vis spectroscopy (Agilent Cary 100 UV-Vis spectrophotometer), and the chemical composition analysis by XPS (Leybold LHS 10/12) , and the vibration mode by Raman spectroscopy.

\section{Material And Method}




\subsection{Experimental: Synthesis of nitrogen-Doped $\mathrm{TiO}_{2}$ cluster}

SCBD was employed to prepare pure and nitrogen-doped $\mathrm{TiO}_{2}$ nanostructured films on silicon and quartz substrates, using a Pulsed Micro-Plasma Cluster Source (PMCS) from LGM laboratory at CIMalNa (Università degli Studi di Milano)(Barborini et al. 1999; Milani et al. 2001; Piseri et al. 1998): a pulsed electric-discharge between the target-material $(\mathrm{Ti})$ - as the cathode - and a second electrode - as the anode - vaporizes the target via sputtering ablation. The discharge is confined to a micro-plasma region at the cathode surface through controlled injection of a process gas (inert: typically He or Ar for metallic clusters, or an oxygen-containing mixture for oxide nanoparticles) with a pulsed solenoid valve. precise control of the gas mixture allows fine tuning on the composition of the nanoparticles that are formed upon condensation of the vapor(D'Elia et al. 2020): for $\mathrm{N}$-doped $\mathrm{TiO}_{2}, 99.80 \%(\mathrm{Ar}), 0.015 \%\left(\mathrm{O}_{2}\right)$, and $0.05 \%\left(\mathrm{~N}_{2}\right)$ were used. The thus-formed nanoparticles suspension is evacuated from the PMCS via a nozzle, generating a seeded supersonic beam of nanoparticles that can be deposited on any substrate intercepting the beam along the propagation direction.

\subsection{Theoretical: Computational methods (DFT)}

To obtain the optimized structure, the configuration is geometrically fully relaxed using the DFT model. To compute the electronic and vibrational properties of pure and $\mathrm{N}$-doped $\mathrm{TiO}_{2}$, we used quantum chemical calculations DFT (Gaussian 16 program package) and Quantum ESPRESSO. The PBE functional(Giannozzi et al. 2009), ultra soft Vanderbilt pseudopotentials(Kresse and Joubert 1999), and a plane-wave (PWs) basis set with a cut off of charge density (30 Ry and 300 Ry) were used to perform structural relaxations with the code Quantum ESPRESSO simulation package. We used Gaussian 16 (Frisch et al. 2020) with hybrid B3LYP(Lee et al. 1988) functional basis sets 6-31G(d) to compute the electric and vibrational modes other than plane waves (PWs). Fig. 1 depicts an optimized structure of $\left(\mathrm{TiO}_{2}\right)_{\mathrm{n}}: \mathrm{Ti}_{9} \mathrm{O}_{18}$ and $\mathrm{Ti}_{28} \mathrm{O}_{56}$. It was chosen from among the structures determined by global optimization using interatomic potentials in recent works(Lamiel-Garcia et al. 2017).

\section{Results And Discussions}

3.1 Bond lengths and formation energies: substitutional and interstitial case of $\left(\mathrm{Ti}_{28} \mathrm{O}_{55} \mathrm{~N}_{7}\right)$ and $\mathrm{TiO}_{2}$ $\left(\mathrm{Ti}_{28} \mathrm{O}_{56} \mathrm{~N}_{7}\right)$ cluster in different configuration

When the nitrogen substituents incorporate into the $\mathrm{TiO}_{2}$, the formation energy altered function of impurity position and $\mathrm{Ti}-\mathrm{N}$ bond lengths are of course altered compared to the pristine $\mathrm{Ti}-\mathrm{O}$ bonds. Several additional publications have noted the effect of impurity location on $\mathrm{TiO}_{2}$ electronic characteristics. Giovanni Di Liberto et al. (Di Liberto et al. 2019) investigated nitrogen doping that is exposed to (001)-(101) Anatase $\mathrm{TiO}_{2}$ Surfaces and discovered that N001 is the most stable doping arrangement, with the nitrogen atom on the (001) side of the interface. kakil et al. (Kakil et al. 2020) demonstrated that nitrogen doping in $\mathrm{TiO}_{2}$ anatase is subsurface depth dependent in substitution and 
interstitial doped forms, and that nitrogen impurity locations are dependent on nanocrystal facet (Kakil et al. 2021). They also investigated the formation of nitrogen impurity in $\mathrm{TiO}_{2}$ nanoparticles and how the mid-gap state of $\mathrm{TiO}_{2}$ nanocrystal is generated, as well as how the nitrogen impurity locations depend on facet of nanocrystal.

Figure 2 shows the optimal structure of $\mathrm{Ti}_{28} \mathrm{O}_{55} \mathrm{~N}_{1}$ obtained by inserting one substitution $\mathrm{N}$ atom in an $\mathrm{O}$ lattice location in various configurations using DFT/PBE. Each number in Table 1 corresponds to the formation energies of nitrogen doped $\mathrm{TiO}_{2}\left(\mathrm{Ti}_{28} \mathrm{O}_{55} \mathrm{~N}_{1}\right)$ at various sites. Ns-Cl.n Ns is for Nitrogen substitution doped, and $\mathrm{Cl} . \mathrm{n}$ stands for impurity at various positions in the cluster, with $\mathrm{n}$ ranging from 1 to 9, corresponding to each location in Figure 2. Equation 1 was used to calculate the formation energies of nitrogen substitution sites.

$$
E_{f}=E_{1 \text { Nnanocluster }}-E_{\text {nanocluster }}+\frac{1}{2} E_{O_{2}}-\frac{1}{2} E_{N_{2}}(1)
$$

Table 1 shows the formation energy and defect gap of a substitution-N-doped $\left(\mathrm{Ti}_{28} \mathrm{O}_{55} \mathrm{~N}_{1}\right)$ nanocluster at various positions. The formation energy varied from 5.321-4.685 eV, whereas the defect energy varied from 1.314 to $0.696 \mathrm{eV}$. As seen in (Ns-Cl6, Ns-Cl7, Ns-Cl8, and Ns-Cl9), the nitrogen atom inside the cluster has lower formation energy than the nitrogen atom outside the cluster. The formation energy of cluster $\mathrm{Ns}-\mathrm{Cl} 9$ is 4.685 , which is lower than the formation energy of another cluster impurity position. The electronic structure of a cluster is affected by the location of nitrogen impurities. According to Table 1, the energy differences are around $0.625 \mathrm{eV}$, although in the case of clusters, the majority of atoms are at the surface and Atom clusters have considerably different physical and chemical properties than bulk solids of the same composition. The discrepancy arises from the fact that a high proportion of their component atoms are situated at the surface. Fig. 4 depicts the influence of impurity position on bond-length change of various substitution positions of nitrogen dopants in the $\left(\mathrm{Ti}_{28} \mathrm{O}_{55} \mathrm{~N} 1\right)$ cluster.

We doped $\mathrm{TiO}_{2}$ in four distinct sites for nitrogen to explore interstitial $\mathrm{N}$ doping, as illustrated in Fig. 3 . Equation 2 is used to compute the formation energy.

$$
E_{f}=E_{1 N \text { nanocluster }}-E_{\text {nanocluster }}-\frac{1}{2} E_{N_{1}}
$$

The formation energy, defect gap, and $\mathrm{N}-\mathrm{O}$ bond length of interstitial - $\mathrm{N}$-doped $\left(\mathrm{Ti}_{28} \mathrm{O}_{56} \mathrm{~N}_{1}\right)$ clusters at different positions are shown in Table 2. The influence of impurity position on defect gap and the $\mathrm{N}-\mathrm{O}$ bond produced in the case of interstitial have different lengths depending on impurity position. Because of the low formation energy, interstitial is more beneficial than substitution in terms of impurity position. We studied (Ni-Cl.4) for the electronic structure investigation because it has a lower formation.

\section{Table 1}


Formation energy $\left(\mathrm{E}_{\mathrm{f}}\right)$ and the defect gap $\left(\mathrm{E}_{\mathrm{IL}}-\mathrm{E}_{\mathrm{VB}}\right)$ of substitutional-N-doped $\left(\mathrm{Ti}_{28} \mathrm{O}_{55} \mathrm{~N}_{1}\right)$ nanocluster ata differentposition.

\begin{tabular}{|lll|}
\hline $\mathrm{Ti}_{28} \mathrm{O}_{55} \mathrm{~N}_{1}$ & $\mathrm{E}_{\mathrm{f}}[\mathrm{eV}]$ & $\mathrm{E}_{\mathrm{IL}}-\mathrm{E}_{\mathrm{V}}[\mathrm{eV}]$ \\
\hline $\mathrm{Ns}-\mathrm{Cl} .1$ & 5.321 & 1.0456 \\
\hline $\mathrm{Ns}-\mathrm{Cl} .2$ & 5.152 & 0.977 \\
\hline $\mathrm{Ns}-\mathrm{Cl} .3$ & 5.125 & 0.696 \\
\hline $\mathrm{Ns}-\mathrm{Cl} .4$ & 5.070 & 1.041 \\
\hline $\mathrm{Ns}-\mathrm{Cl} .5$ & 5.080 & 1.326 \\
\hline $\mathrm{Ns}-\mathrm{Cl} .6$ & 5.018 & 1.259 \\
\hline $\mathrm{Ns}-\mathrm{Cl} .7$ & 5.052 & 0.965 \\
\hline $\mathrm{Ns}-\mathrm{Cl} .8$ & 4.869 & 1.270 \\
\hline $\mathrm{Ns}-\mathrm{Cl} .9$ & 4.685 & 1.314 \\
\hline
\end{tabular}

\subsection{Electronic properties of pure $\mathrm{Ti}_{28} \mathrm{O}_{56}$ and nitrogen doped $\left(\mathrm{Ti}_{28} \mathrm{O}_{56} \mathrm{~N}_{1}\right)$}

The density of State (DOS) was computed using Gaussian16 software to investigate the electrical characteristics of the examined structures. Any material's electronic density of states provides enough information to comprehend its electronic characteristics fully. A density-of-state (DOS) diagram can be used to visualize the energy level distribution (Gui et al. 2019). $\mathrm{TiO}_{2}$ and $\mathrm{N}$-doped $\mathrm{TiO}_{2}$, nanocluster wave function was calculated using Density Functional Theory (DFT), B3LYP at 6-31G(d) basis set. Fig. 5 compares the density of states (DOS) for pure $\left(\mathrm{Ti}_{28} \mathrm{O}_{56}\right)$ and nitrogen doped $\left(\mathrm{Ti}_{28} \mathrm{O}_{55} \mathrm{~N}_{1}\right)$ Nano clusters. Significant impurity states are introduced into the gap as a result of doping. Following the addition of one nitrogen, the states emerge at the top of the conduction band. N's action defines the creation of the ionic $\mathrm{N}-\mathrm{O}$ bond as a p dopant. $\mathrm{N}(\mathrm{p})$ helps to narrow the gap by producing the valence and conduction bands.

After the Nitrogen atom was inserted into the $\mathrm{TiO}_{2}$ structure, the HUMO-LUMO gap was reduced from $3.772 \mathrm{eV}$ to $2.389 \mathrm{eV}$. A significant change can be seen in these graphs. UV absorption spectra, which will be examined in the next section, revealed this behavior. Because the band gap of the Quantum Espresso/PBE-GGA method was underestimated, we employed the Gaussian/B3LYP approach. The gap energy reduces from 2.826 to $1.257 \mathrm{eV}$ calculated by Quantum Espresso /PBE-GGA, as shown in Table 3. The electronic band and defect band in [eV] for pure $\mathrm{Ti}_{28} \mathrm{O}_{56}$ and nitrogen doped $\mathrm{TiO}_{2}\left(\mathrm{Ti}_{28} \mathrm{O}_{56} \mathrm{~N}_{1}\right)$ were calculated using both Quantum Espresso /PBE-GGA and Gaussian/B3LYP/6-31G(d) approaches, and the 
results were compared to previous literature(Cao et al. 2021; Lundqvist et al. 2006; Oprea and Gîrțu 2019; Persson et al. 2000; Selli et al. 2017).

\section{Table 2}

Formation energy $\left(\mathrm{E}_{\mathrm{f}}\right)$, the defect gap $\left(\mathrm{E}_{\mathrm{LL}}-\mathrm{E}_{\mathrm{VB}}\right)$, and N-O bond length of interstitial -N-doped $\left(\mathrm{Ti}_{28} \mathrm{O}_{56} \mathrm{~N}_{1}\right)$ cluster at a different position.

\begin{tabular}{|llll|}
\hline $\mathrm{Ti}_{28} \mathrm{O}_{56} \mathrm{~N}_{\mathbf{1}}$ & $\mathrm{E}_{f}[\mathrm{eV}]$ & $\mathrm{E}_{\mathrm{IL}}-\mathrm{E}_{\mathrm{V}}[\mathrm{eV}]$ & $\mathrm{N}-\mathrm{O}[\mathrm{pm}]$ \\
\hline $\mathrm{Ni}-\mathrm{Cl} .1$ & 3.910 & 1.617 & 137 \\
$\mathrm{Ni}-\mathrm{Cl} .2$ & 3.820 & 0.914 & 133 \\
$\mathrm{Ni}-\mathrm{Cr} .3$ & 3.527 & 1.291 & 135 \\
\hline $\mathrm{Ni}-\mathrm{Cl} .4$ & 2.9 & 1.253 & 134 \\
\hline
\end{tabular}

\section{Table 3}

TheBandgap and defect gap inunit [eV] for pure $\mathrm{Ti}_{28} \mathrm{O}_{56}$ and nitrogen doped $\mathrm{TiO}_{2}\left(\mathrm{Ti}_{28} \mathrm{O}_{56} \mathrm{~N}_{1}\right)$ utilizing Q.E espresso /PBE-GGA and Gaussian/B3LYP /6-31G (d)methods.

\begin{tabular}{|c|c|c|c|}
\hline Cluster & Method & Band gap [eV] & Defect band gap[eV] \\
\hline $\mathrm{Ti}_{28} \mathrm{O}_{56}$ & PBE & $2.826^{\text {[this work] }}$ & 1.257 \\
\hline $\mathrm{Ti}_{28} \mathrm{O}_{56}$ & B3LYP/6-31G(d) & $3.772^{[\text {this work }]}$ & 2.893 \\
\hline $\mathrm{Ti}_{28} \mathrm{O}_{56}$ & B3LYP/VDZ//PW/SZ & $3.67^{[27]}$ & \\
\hline$\left(\mathrm{TiO}_{2}\right)_{101} \cdot 6 \mathrm{H} 2 \mathrm{O}$ & DFT(B3LYP) & $3.81^{[28]}$ & \\
\hline $\mathrm{Ti}_{24} \mathrm{O}_{50} \mathrm{H}$ & B3LYP/LANL2DZ & $3.8^{[29]}$ & \\
\hline$\left(\mathrm{TiO}_{2}\right)_{101} \cdot 6 \mathrm{H} 2 \mathrm{O}$ & DFTB & $3.2^{[28]}$ & \\
\hline $\mathrm{Ti}_{29} \mathrm{O}_{58}$ & Gaussian03/B3LYP/6311G & $3.33^{[30]}$ & \\
\hline $\mathrm{Ti}_{38} \mathrm{O}_{76}$ & INDO/S-Cl & $3.5^{[31]}$ & \\
\hline
\end{tabular}

\subsection{Surface morphology of $\mathrm{N}$-doped $\mathrm{TiO}_{2}$ nanocluster}

Atomic force microscopy AFM was used to analyze the surface morphology of nanostructured Nitrogendoped $\mathrm{TiO}_{2}$. Fig. 6 shows the surface morphology of the $\mathrm{N}$ doped $\mathrm{TiO}_{2}$ cluster layer formed on silicon and a histogram of particle size distribution. As seen in the histogram, the clusters appear to be almost 
spherical, with an average lateral size of less than $(2 \mathrm{~nm})$ and some of them having an average size of 5 $\mathrm{nm}$. The smallest visible grains $(2 \mathrm{~nm})$ are primeval clusters created in the source, while larger grains produce smaller clusters aggregating and coalescing.

\subsection{X-ray Photoelectron Spectroscopy (XPS)}

XPS analysis was used to analyze the chemical composition and chemical state of the $\mathrm{TiO}_{2}$ nanoclusters. Fig. 7 shows the XPS spectra of $\mathrm{N}$-doped $\mathrm{TiO}_{2}$, where the peaks at 401.7, 459, 464, and $530.17 \mathrm{eV}$ correspond to the binding energy of $\mathrm{N} 1 \mathrm{~s}, \mathrm{Ti}_{2} \mathrm{P}_{1 / 2}, \mathrm{Ti}_{2} \mathrm{P}_{3 / 2}$, and $\mathrm{O} 1 \mathrm{~s}$ peaks. The $\mathrm{N} 1 \mathrm{~s}$ reveal the presence of nitrogen in the nanostructured material (inset Fig. 7). The peaks are in the range (396-404 eV) seen by numerous other writers, although Di Valentin et al (Di Valentin et al. 2007) detected a peak at higher binding energy $(400 \mathrm{eV})$. This peak at this energy represents the interstitial-site nitrogen $(\mathrm{Ti}-\mathrm{O}-\mathrm{N})$ in which the $\mathrm{N}$ atoms are bound to lattice oxygen atoms. This peak at this energy represents the interstitial-site nitrogen.

\subsection{Optical properties of the pure and nitrogen-doped $\mathrm{TiO}_{2}$}

A UV- visible absorption spectrum was performed to analyze the optical absorbance of pure and nitrogendoped $\mathrm{TiO}_{2}$ nanoclusters. If the semiconductor size is smaller than the Bohr radius of the excited state, the quantum confinement effect is expected, and the absorption edge will be shifted to higher energy. More study is being done on the quantum confinement effect of $\mathrm{TiO}_{2}$ as well as direct and indirect band gaps. Yin Zhao and Chunzhong Li et al (Zhao et al. 2007)found that the band gap of as-prepared $\mathrm{TiO}_{2}$ nanoparticles is $3.28 \mathrm{eV}$, which is somewhat higher than the value of $3.2 \mathrm{eV}$ for bulk $\mathrm{TiO}_{2}$ due to the quantum size impact of the present $\mathrm{TiO}_{2}$. In anatase $\mathrm{TiO}_{2}$ nanoparticles, $\mathrm{K}$. Madhusudan Reddy et al (Madhusudan Reddy et al. 2003) indicated that the direct, rather than indirect, transition is more beneficial, as shown in Table 4. Fig. 8 shows the UV-vis spectra of pure and Nitrogen-doped $\left(\mathrm{TiO}_{2}\right)$ nanostructures. The plots of (a.hv) ${ }^{2}$ vs the energy level of the absorbed light are shown in the inset Fig. 8. The Wood and Tauc equation, which is defined as follows, is used to estimate the band gap value.

\section{Table 4}

Experimental Band Gap in unit [eV] forpure and Nitrogen-doped $\mathrm{TiO}_{2}$ compared with previous works. 


\begin{tabular}{|llll|}
\hline Nano composites & Size $[\mathrm{nm}]$ & Bandgap [eV] & Ref \\
\hline $\mathrm{TiO}_{2}$ nanocluster & $2-5$ & 3.75 & This work \\
$\mathrm{N}-\mathrm{TiO}_{2}$ nanocluster & $2-5$ & 3.56 & This work \\
\hline Quantum dot & 5 & $\sim 3.76$ & {$[37]$} \\
\hline Quantum dot & $3-7$ & 3.79 & {$[38]$} \\
\hline Nanoparticle & 11 & 3.4 & {$[12]$} \\
\hline Nanoparticle & 10 & 3.35 & {$[35]$} \\
N-doped nanoparticle & 10 & 3.05 & \\
\hline Nanoparticle & 20 & 3.75 & {$[13]$} \\
\hline
\end{tabular}

$\alpha \mathrm{h} \nu=\mathrm{K}\left(\mathrm{h} \nu-\mathrm{E}_{\mathrm{g}}\right)^{\mathrm{n}}(3)$

Where $\mathrm{K}, \mathrm{hv}$, and Eg are constant, photon energy, and optical band gap, respectively. $\mathrm{n}$ is equal to $1 / 2$ for allowed direct optical transitions, and $a$ is the absorption coefficient. The band gap values were determined by extrapolating the linear region of the plot to $h v=0$. From the Tauc plots of $(a h v)^{2}$ versus hv. The direct band gap of $\mathrm{TiO}_{2}$ nanopartical observed (Jia et al. 2018; Karkare 2014; Mahmoud et al. 2021; Mandal et al. 2019) With the addition of nitrogen atom, the band gap decreased from 3.75 to 3.560 $\mathrm{eV}$, and the results were summarized in Table 4. It displays the experimental measurements of band gap in [eV] units and compares them with previous works (Gnanasekaran et al. 2015; Javed et al. 2019; Jia et al. 2018; Karkare 2014; Mandal et al. 2019). Because its $p$ states contribute to band gap narrowing by mixing with $02 p$ and $N(p)$ states, the $N$ atom's lowered band gap was the most effective. The excitation wavelengths were found by DFT (B3LYP/6-31G(d)) for pure and nitrogen-doped $\mathrm{TiO}_{2}(350.96$ and 411.00 $\mathrm{nm})$, respectively.

\subsection{Experimental and theoretical DFTB3LYP/6-31G (d) investigation of Raman spectra for pure and nitrogen doped $\mathrm{TiO}_{2}$}

\subsubsection{Raman analysis}

The following representation for optical vibrational modes at the $\Gamma$ point of bulk $\mathrm{TiO}_{2}$ was derived from a group theoretical analysis:

$A_{1 g}+1 A_{2 u}+2 B_{1 g}+1 B_{2 u}+3 E_{g}+2 E_{u}$

It consists of three Raman active modes $\left(A_{1 g}+1 B_{1 g}+3 E_{g}\right)$, two modes are infrared active $\left(1 A_{2 u}+2 E_{u}\right)$, and one mode $\left(1 \mathrm{~B}_{2 \mathrm{u}}\right)$ is inactive in both Raman and infrared(Ohsaka 1980). The vibration mode of $\mathrm{TiO}_{2}$ 
was impacted by size, annealing, architectures, and other factors; Xu et al. (Xu et al. 2001) explained the variation in the Raman bands with a phonon confinement model based on the Heisenberg uncertainty principle. They showed that the phonon becomes increasingly confined within the particle and the phonon momentum distribution as particle size decreases.

Flavio Della Foglia et al. (Della Foglia et al. 2009) synthesized the $\mathrm{TiO}_{2}$ nanostructured film via (SCBD). Raman spectroscopy indicated no crystalline structure after annealing at $200^{\circ} \mathrm{C}$, indicating that the film is predominantly amorphous. They also demonstrated that the shape of nanostructured $\mathrm{TiO}_{2}$ films could improve annealing for photocatalytic applications. Hengzhong Zhang (Zhang et al. 2008) reported a combination of experimental and computational modeling to investigate amorphous titanium made up of $2 \mathrm{~nm} \mathrm{TiO}{ }_{2}$ nanoparticles. The nanoparticles contain a severely deformed shell and a stretched anatase-like core, according to the researchers. The weak Raman scattering in these films is attributed to the low phonon density of states in the amorphous phase, as seen in Fig. 9, which exhibits Raman spectra of pure and Nitrogen-doped $\mathrm{TiO}_{2}$ clusters without annealing. The no observed Raman bands in an amorphous solid are no longer related to traveling waves or wave vectors, as are no longer phonons.

\subsubsection{Theoretical vibrational properties of pure and $\mathrm{N}-$ doped (TiO2)n by DFT / B3LYP/6-31G(d)}

Ogata et al. (Ogata et al. 1999) employed modified variable charge interatomic potential to examine the structural and physical features of nano size $\mathrm{TiO}_{2}$ clusters of 1050 and 672 atoms at $100 \mathrm{~K}$ using molecular dynamics (MD) simulations. We reveal the Ti-O bonding characteristics that play a key role in replicating macroscopic and microscopic values with accuracy comparable to that of first-principles computations. Kulbir Kaur Ghuman et al.(Ghuman et al. 2013) investigated the vibrational characteristics of rutile supercells and rutile and amorphous $\mathrm{TiO}_{2}$ nanoparticles using the Matsui and Akaogi rigid ion model with effective charges on $\mathrm{Ti}$ and $\mathrm{O}$ atoms. They demonstrated that the phonon bandwidth and dispersive character of optical phonon modes in higher frequency ranges agree with experimental results. However, the calculated and experimental findings are within $15 \%$ of each other in the intermediate energy range, while the calculated results are higher than the experimental values in the lower energy range.

In a $\left(\mathrm{TiO}_{2}\right)_{\mathrm{n}}$ cluster, if $\mathrm{n}$ changes, the majority of physical properties change as well. The clusters were constructed by Brandon Bukowski et al. (Bukowski and Deskins 2015) with $n=1,3,5,8$, and 15 total atoms, or 3, 9, 15, 24, and 45 total atoms, respectively. For each cluster size, there are a number of possible structural isomers. When a result, as cluster sizes get larger, atoms tend to adopt higher coordination, eventually embracing bulk coordination with the correct cluster size.

The vibrational modes of $\mathrm{Ti}_{9} \mathrm{O}_{18}$ and $\mathrm{Ti}_{28} \mathrm{O}_{56}$ clusters were calculated in this study. Except for $\mathrm{Ti}_{2} \mathrm{O}_{4}$ spectral investigation (Majid and Bibi 2017), none of the above physical attributes have been explored by any other researcher. 
Because there are multiple coordinates of $\mathrm{Ti}(1 \mathrm{Ti}, 2 \mathrm{Ti}, 3 \mathrm{Ti} \ldots .$.$) for any given cluster size, we have 74$ modes of vibration in $\mathrm{Ti}_{9} \mathrm{O}_{18}$ clusters, the majority of which are different from $\mathrm{Ti}_{2} \mathrm{O}_{4}$ due to different structures. As cluster sizes rise, the atoms tend to adopt higher coordination, as shown in Fig. 10, which shows the Raman activity spectra of $\mathrm{Ti}_{9} \mathrm{O}_{18}$ and $\mathrm{Ti}_{2} 8 \mathrm{O}_{56}$ computed using Gaussian/ B3LYP 6-31G (d), with two strong peaks appearing about $1040.92 \mathrm{~cm}^{-1}$ and $1045.45 \mathrm{~cm}^{-1}$. These two vibrations do not exist in the cluster $\left(\mathrm{Ti}_{28} \mathrm{O}_{56}\right)$ because both cluster sides have $1 \mathrm{Ti}$ coordinates, as shown in Fig. 11. The arrow represents the $0-1 \mathrm{Ti}$ vibration mode. We believe all clusters cannot have the same vibration, which is dependent on cluster structure. The Raman spectrum activity of pure $\left(\mathrm{Ti}_{28} \mathrm{O}_{56}\right)$ and nitrogen doped $\left(\mathrm{Ti}_{28} \mathrm{O}_{56} \mathrm{~N}_{1}\right)$ Nano clusters are displayed in Fig. 12 using Gaussian/ B3LYP/6-31G (d). The (*) peak of pure Ti-O demonstrates the stretched bonds $\left(\mathrm{Ti}_{28} \mathrm{O}_{56}\right)$. The vibrational mode $\mathrm{N}-\mathrm{O}$ of nitrogen doped $\left(\mathrm{Ti}^{28} \mathrm{O} 5^{6} \mathrm{~N}^{1}\right)$ at approximately $1013.9 \mathrm{~cm}^{-1}$ is depicted in the inset Fig. 13 . This is a stretching mode that has been investigated in $\mathrm{N}$-doped $\mathrm{TiO}_{2}$.

\section{Conclusions}

The following goals are pursued using experimental and theoretical studies (DFT/B3LYP/6-31G (d) techniques and the Quantum espresso code).

i. Structural and Electronic characteristics of pure and nitrogen doped $\left(\mathrm{TiO}_{2}\right)_{\mathrm{n}}$ clusters were examined using two DFT level theories: Quantum Espresso/PBE and Gaussian/B3LYP/6-31G (d).

ii. The synthesis of $\mathrm{TiO}_{2}$ and nitrogen doped $\mathrm{TiO}_{2}$ nanoclusters was achieved using Supersonic Cluster Beam Deposition (SCBD). The size of the particles is estimated to be in the range of (2-5 nm).

iii. We discovered the effect of impurity position on formation energy and electronic characteristics in both interstitial and substitution cases in an optimized structure. We assumed that doped nitrogen in $\mathrm{TiO}_{2}$ clusters is positioned at the interstitial site of the $\mathrm{TiO}_{2}$ lattice based on formation energy, which is compatible with XPS data (O-Ti-N).

iv. The band gap energy dropped for the $\mathrm{N}$-doped $\mathrm{TiO}_{2}$ clusters, according to UV-Vis spectroscopy. As a result of the theoretical conclusions, the band gap is predicted to decrease when $\mathrm{N}$ is doped.

v. The addition of $\mathrm{N}$ as a dopant result in forming a new $\mathrm{N}-\mathrm{O}$ band with the vibration of $\left(1013.91 \mathrm{~cm}^{-1}\right)$ at Gaussian/B3LYP/6-31G (d), implying the emergence of states in band states with a narrowing of the bandgap.

vi. The quantum confinement effect was observed using UV-Vis Spectroscopy, with a significant band gap energy of pure $\mathrm{TiO}_{2}(3.753 \mathrm{eV}$ ) and the theoretical band gap (3.772 eV) via DFT/B3LYP/6-31G (d) basis set.

vii. Raman spectral activity of $\mathrm{Ti}_{9} \mathrm{O}_{18}$ and $\mathrm{Ti}_{28} \mathrm{O}_{56}$ nano clusters has been studied using Gaussian/ B3LYP/6-31G (d) basis set.

viii. We believe this research is important because it has the potential to aid in the study and characterization of the physics and materials science of $\mathrm{TiO}_{2}$. This material that has received a lot of 
attention in recent years. Due to its significance for titanium nanocluster, it may also have an impact on nanoscience.

\section{Declarations}

\section{Acknowledgments}

The authors would like to thank Nicola Manini from UniversitadegliStudi di Milano-Italy for providing computational facilities and outstanding scientific advice. Special thanks to Alessandro Podestà and Paolo Piseri from CIMalna laboratories at UniversitàdegliStudi di Milano (Milano, Italy), for their facilities to access samples and perform characterization. The scientific support in the etsfmi group, especially Elena Molteni and Guido Fratesi are acknowledged.

\section{Conflict of Interest}

The authors declare no conflict of interest.

\section{References}

1. Arab, A., Ziari, F., Fazli, M.: Electronic structure and reactivity of (TiO2)n ( $n=1-10)$ nano-clusters: Global and local hardness based DFT study. Computational Materials Science. 117, 90-97 (2016). https://doi.org/https://doi.org/10.1016/j.commatsci.2016.01.031

2. Barborini, E., Piseri, P., Milani, P.: A pulsed microplasma source of high intensity supersonic carbon cluster beams. Journal of Physics D: Applied Physics. 32, L105-L109 (1999). https://doi.org/10.1088/0022-3727/32/21/102

3. Bukowski, B., Deskins, N.A.: The interactions between TiO2 and graphene with surface inhomogeneity determined using density functional theory. Physical Chemistry Chemical Physics. 17, 29734-29746 (2015). https://doi.org/10.1039/C5CP04073F

4. Cao, F., 怄, Tan, K., 怄, Lin, M.-H., 怄区, Zhang, Q.-E., 眈: A Density Functional Study of N-Doped TiO2 Anatase Cluster. (2021)

5. Chiodi, M., Cheney, C.P., Vilmercati, P., Cavaliere, E., Mannella, N., Weitering, H.H., Gavioli, L.:

Enhanced Dopant Solubility and Visible-Light Absorption in $\mathrm{Cr}-\mathrm{N}$ Codoped TiO2 Nanoclusters. The Journal of Physical Chemistry C. 116, 311-318 (2012). https://doi.org/10.1021/jp208834n

6. D’Elia, A., Cepek, C., de Simone, M., Macis, S., Belec, B., Fanetti, M., Piseri, P., Marcelli, A., Coreno, M.: Interplay among work function, electronic structure and stoichiometry in nanostructured VOx films. Physical Chemistry Chemical Physics. 22, 6282-6290 (2020). https://doi.org/10.1039/D0CP00216J

7. Drabik, M., Choukourov, A., Artemenko, A., Polonskyi, O., Kylian, O., Kousal, J., Nichtova, L., Cimrova, V., Slavinska, D., Biederman, H.: Structure and Composition of Titanium Nanocluster Films Prepared by a Gas Aggregation Cluster Source. The Journal of Physical Chemistry C. 115, 20937-20944 (2011). https://doi.org/10.1021/jp2059485 
8. Della Foglia, F., Losco, T., Piseri, P., Milani, P., Selli, E.: Photocatalytic activity of nanostructured TiO2 films produced by supersonic cluster beam deposition. Journal of Nanoparticle Research. 11, 13391348 (2009). https://doi.org/10.1007/s11051-009-9691-1

9. Frisch, M.J., Trucks, G.W., Schlegel, H.B., Scuseria, G.E., Robb, M.A., Cheeseman, J.R., Scalmani, G., Barone, V., Petersson, G.A., Nakatsuji, H.: Gaussian 16, Revision C. 01. Gaussian, Inc., Wallingford CT. 2016. Google Scholar There is no corresponding record for this reference. (2020)

10. Fronzi, M., Iwaszuk, A., Lucid, A., Nolan, M.: Metal oxide nanocluster-modified TiO2 as solar activated photocatalyst materials. Journal of physics. Condensed matter: an Institute of Physics journal. 28, 74006 (2016). https:// doi.org/10.1088/0953-8984/28/7/074006

11. Ghuman, K.K., Goyal, N., Prakash, S.: Vibrational density of states of TiO2 nanoparticles. Journal of Non-Crystalline Solids. 373-374, 28-33 (2013).

https://doi.org/https://doi.org/10.1016/j.jnoncrysol.2013.04.022

12. Giannozzi, P., Baroni, S., Bonini, N., Calandra, M., Car, R., Cavazzoni, C., Ceresoli, D., Chiarotti, G.L., Cococcioni, M., Dabo, I., Dal Corso, A., de Gironcoli, S., Fabris, S., Fratesi, G., Gebauer, R., Gerstmann, U., Gougoussis, C., Kokalj, A., Lazzeri, M., Martin-Samos, L., Marzari, N., Mauri, F., Mazzarello, R., Paolini, S., Pasquarello, A., Paulatto, L., Sbraccia, C., Scandolo, S., Sclauzero, G., Seitsonen, A.P., Smogunov, A., Umari, P., Wentzcovitch, R.M.: QUANTUM ESPRESSO: a modular and open-source software project for quantum simulations of materials. Journal of Physics: Condensed Matter. 21, 395502 (2009). https://doi.org/10.1088/0953-8984/21/39/395502

13. Gnanasekaran, L., Hemamalini, R., Ravichandran, K.: Synthesis and characterization of TiO2 quantum dots for photocatalytic application. Journal of Saudi Chemical Society. 19, 589-594 (2015). https://doi.org/https://doi.org/10.1016/j.jscs.2015.05.002

14. Gui, Y., Liu, D., Li, X., Tang, C., Zhou, Q.: DFT-based study on H2S and SOF2 adsorption on Si-MoS2 monolayer. Results in Physics. 13, 102225 (2019).

https://doi.org/https://doi.org/10.1016/j.rinp.2019.102225

15. Javed, S., Islam, M., Mujahid, M.: Synthesis and characterization of TiO2 quantum dots by sol gel reflux condensation method. Ceramics International. 45, 2676-2679 (2019).

https://doi.org/https://doi.org/10.1016/j.ceramint.2018.10.163

16. Jia, T., Fu, F., Yu, D., Cao, J., Sun, G.: Facile synthesis and characterization of N-doped TiO2/C nanocomposites with enhanced visible-light photocatalytic performance. Applied Surface Science. 430, 438-447 (2018). https://doi.org/https://doi.org/10.1016/j.apsusc.2017.07.024

17. Kakil, S.A., Abdullah, hewa Y., Abdullah, T.G., Manini, N.: Subsurface depth dependence of nitrogen doping in TiO2 anatase: a DFT study. Journal of Physics: Condensed Matter. (2020). https://doi.org/10.1088/1361-648X/abce41

18. Kakil, S.A., Abdullah, H.Y., Abdullah, T.G.: Electronic properties of (TiO2)33 nanocrystals with nitrogen impurities at different facets: a DFT study. Molecular Simulation. 1-13 (2021). https://doi.org/10.1080/08927022.2021.1962010 
19. Karkare, M.M.: Estimation of band gap and particle size of TiO2 nanoparticle synthesized using sol gel technique. In: 2014 International Conference on Advances in Communication and Computing Technologies (ICACACT 2014). pp. 1-5 (2014)

20. Kresse, G., Joubert, D.: From ultrasoft pseudopotentials to the projector augmented-wave method. Physical Review B. 59, 1758-1775 (1999). https://doi.org/10.1103/PhysRevB.59.1758

21. Lamiel-Garcia, O., Cuko, A., Calatayud, M., Illas, F., Bromley, S.T.: Predicting size-dependent emergence of crystallinity in nanomaterials: titania nanoclusters versus nanocrystals. Nanoscale. 9, 1049-1058 (2017). https://doi.org/10.1039/C6NR05788H

22. Lee, C., Yang, W., Parr, R.G.: Development of the Colle-Salvetti correlation-energy formula into a functional of the electron density. Physical review. B, Condensed matter. 37, 785-789 (1988). https://doi.org/10.1103/physrevb.37.785

23. Di Liberto, G., Tosoni, S., Pacchioni, G.: Nitrogen doping in coexposed (001)-(101) anatase TiO2 surfaces: a DFT study. Physical Chemistry Chemical Physics. 21, 21497-21505 (2019). https://doi.org/10.1039/C9CP03930A

24. Lin, H., Huang, C.P., Li, W., Ni, C., Shah, S.I., Tseng, Y.-H.: Size dependency of nanocrystalline TiO2 on its optical property and photocatalytic reactivity exemplified by 2-chlorophenol. Applied Catalysis B: Environmental. 68, 1-11 (2006). https://doi.org/https://doi.org/10.1016/j.apcatb.2006.07.018

25. Lundqvist, M.J., Nilsing, M., Persson, P., Lunell, S.: DFT study of bare and dye-sensitized TiO2 clusters and nanocrystals. International Journal of Quantum Chemistry. 106, 3214-3234 (2006). https://doi.org/https://doi.org/10.1002/qua.21088

26. Madhusudan Reddy, K., Manorama, S. V, Ramachandra Reddy, A.: Bandgap studies on anatase titanium dioxide nanoparticles. Materials Chemistry and Physics. 78, 239-245 (2003). https://doi.org/https://doi.org/10.1016/S0254-0584(02)00343-7

27. Mahmoud, Z.H., Adham AL-Bayati, R., Khadom, A.A.: Modified anatase phase of TiO2 by WO3 nanoparticles: Structural, morphology and spectral evaluations. Materials Today: Proceedings. (2021). https://doi.org/https://doi.org/10.1016/j.matpr.2021.09.040

28. Majid, A., Bibi, M.: First principles study of vibrational dynamics of ceria-titania hybrid clusters. Journal of Nanoparticle Research. 19, 122 (2017). https://doi.org/10.1007/s11051-017-3823-9

29. Mandal, S., Jain, N., Pandey, M.K., Sreejakumari, S.S., Shukla, P., Chanda, A., Som, S., Das, S., Singh, J.: Ultra-bright emission from Sr doped TiO(2) nanoparticles through r-GO conjugation. Royal Society open science. 6, 190100 (2019). https://doi.org/10.1098/rsos.190100

30. Milani, P., Piseri, P., Barborini, E., Podesta, A., Lenardi, C.: Cluster beam synthesis of nanostructured thin films. Journal of Vacuum Science \& Technology A. 19, 2025-2033 (2001). https://doi.org/10.1116/1.1331289

31. Monticone, Sq. size effect in T. nanoparticles: does it exist?, Tufeu, R., Kanaev, A. V, Scolan, E., Sanchez, C.: Quantum size effect in TiO2 nanoparticles: does it exist? Applied Surface Science. 162163, 565-570 (2000). https://doi.org/https://doi.org/10.1016/S0169-4332(00)00251-8 
32. Ogata, S., Iyetomi, H., Tsuruta, K., Shimojo, F., Kalia, R.K., Nakano, A., Vashishta, P.: Variable-charge interatomic potentials for molecular-dynamics simulations of TiO2. Journal of Applied Physics. 86, 3036-3041 (1999). https://doi.org/10.1063/1.371165

33. Ohsaka, T.: Temperature Dependence of the Raman Spectrum in Anatase TiO2. Journal of the Physical Society of Japan. 48, 1661-1668 (1980). https://doi.org/10.1143/JPSJ.48.1661

34. Oprea, C.I., Gîrțu, M.A.: Structure and Electronic Properties of TiO2 Nanoclusters and DyeNanocluster Systems Appropriate to Model Hybrid Photovoltaic or Photocatalytic Applications, (2019)

35. Persson, P., Bergström, R., Lunell, S.: Quantum Chemical Study of Photoinjection Processes in DyeSensitized TiO2 Nanoparticles. The Journal of Physical Chemistry B. 104, 10348-10351 (2000). https://doi.org/10.1021/jp002550p

36. Piseri, P., Li Bassi, A., Milani, P.: Time-of-flight analysis of neutral cluster beams through detection of charged particles produced by cluster impact on a channeltron. Review of Scientific Instruments. 69, 1647-1649 (1998). https://doi.org/10.1063/1.1148869

37. Qu, Z., Kroes, G.-J.: Theoretical Study of the Electronic Structure and Stability of Titanium Dioxide Clusters (TiO2)n with $n=1-9$. The Journal of Physical Chemistry B. 110, 8998-9007 (2006). https://doi.org/10.1021/jp056607p

38. Salazar-Villanueva, M., Hernandez, A.B., Anota, E.C., Valdez, S., Cuchillo, O.V.: Electronic and structural properties of Ti9XO20 (X=Ti, C, si, Ge, Sn and pb) clusters: A DFT study. Physica E: Lowdimensional Systems and Nanostructures. 65, 120-124 (2015). https://doi.org/https://doi.org/10.1016/j.physe.2014.09.009

39. Selli, D., Fazio, G., Valentin, C.: Using Density Functional Theory to Model Realistic TiO2 Nanoparticles, Their Photoactivation and Interaction with Water. Catalysts. 7, 357 (2017). https://doi.org/10.3390/catal7120357

40. Shyjumon, I., Gopinadhan, M., Helm, C.A., Smirnov, B.M., Hippler, R.: Deposition of titanium/titanium oxide clusters produced by magnetron sputtering. Thin Solid Films. 500, 41-51 (2006). https://doi.org/https://doi.org/10.1016/j.tsf.2005.11.006

41. Srivastava, S., Thomas, J.P., Rahman, M.A., Abd-Ellah, M., Mohapatra, M., Pradhan, D., Heinig, N.F., Leung, K.T.: Size-Selected TiO2 Nanocluster Catalysts for Efficient Photoelectrochemical Water Splitting. ACS Nano. 8, 11891-11898 (2014). https://doi.org/10.1021/nn505705a

42. Di Valentin, C., Finazzi, E., Pacchioni, G., Selloni, A., Livraghi, S., Paganini, M.C., Giamello, E.: N-doped TiO2: Theory and experiment. Chemical Physics. 339, 44-56 (2007). https://doi.org/https://doi.org/10.1016/j.chemphys.2007.07.020

43. Valero, R., Morales-García, Á., Illas, F.: Theoretical Modeling of Electronic Excitations of Gas-Phase and Solvated TiO2 Nanoclusters and Nanoparticles of Interest in Photocatalysis. Journal of Chemical Theory and Computation. 14, 4391-4404 (2018). https://doi.org/10.1021/acs.jctc.8b00651 
44. Xu, C.Y., Zhang, P.X., Yan, L.: Blue shift of Raman peak from coated TiO2 nanoparticles. Journal of Raman Spectroscopy. 32, 862-865 (2001). https://doi.org/https://doi.org/10.1002/jrs.773

45. Zhang, H., Chen, B., Banfield, J.F., Waychunas, G.A.: Atomic structure of nanometer-sized amorphous \$\{text\{TiO\}\}_\{2\}\$. Physical Review B. 78, 214106 (2008).

https://doi.org/10.1103/PhysRevB.78.214106

46. Zhao, Y., Li, C., Liu, X., Gu, F., Jiang, H., Shao, W., Zhang, L., He, Y.: Synthesis and optical properties of TiO2 nanoparticles. Materials Letters. 61, 79-83 (2007). https://doi.org/https://doi.org/10.1016/j.matlet.2006.04.010

\section{Figures}

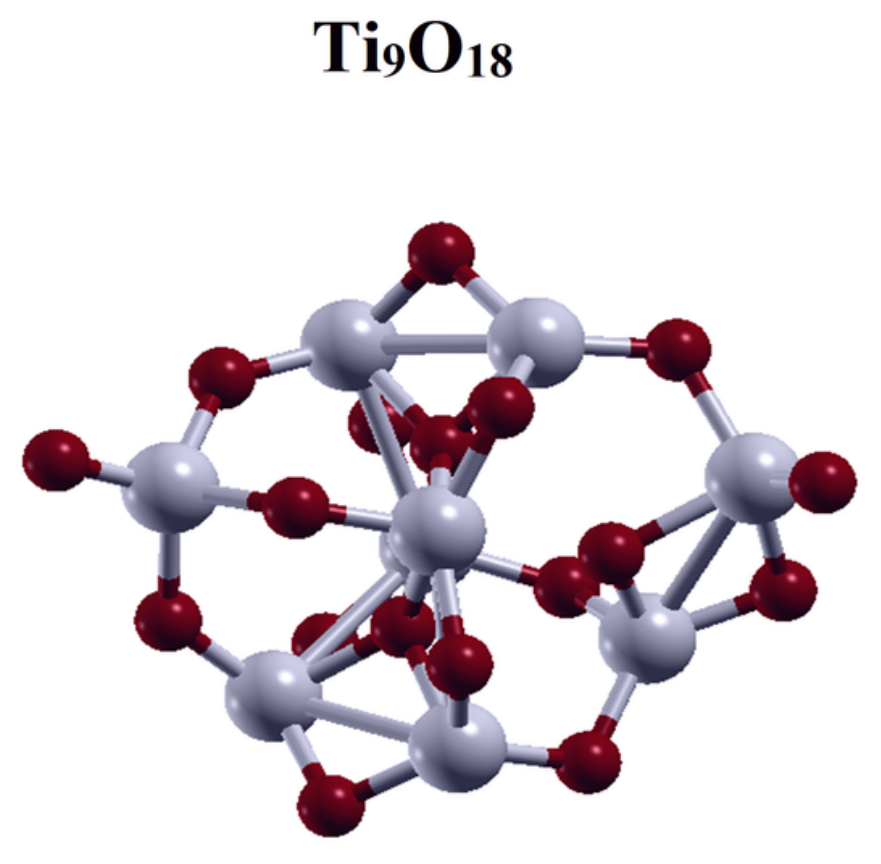

$\mathrm{Ti}_{28} \mathrm{O}_{56}$

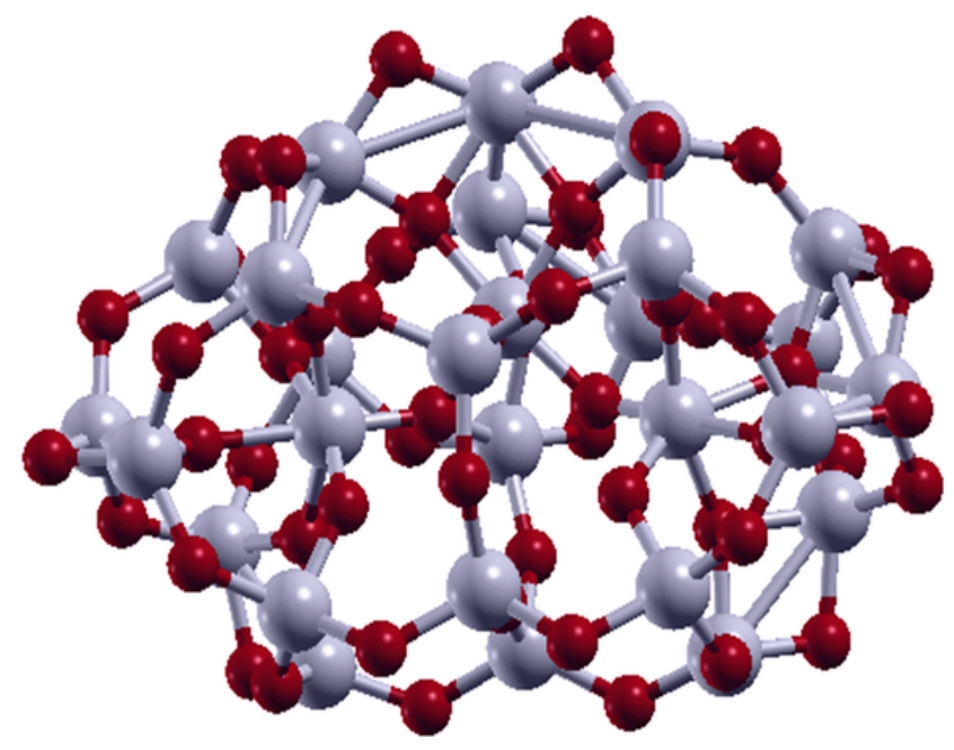

Ti atoms

O atoms

Figure 1

DFT Optimized structure of different nanocluster:Ti9018 andTi28056 by using DFT / Quantum ESPRESSO. 


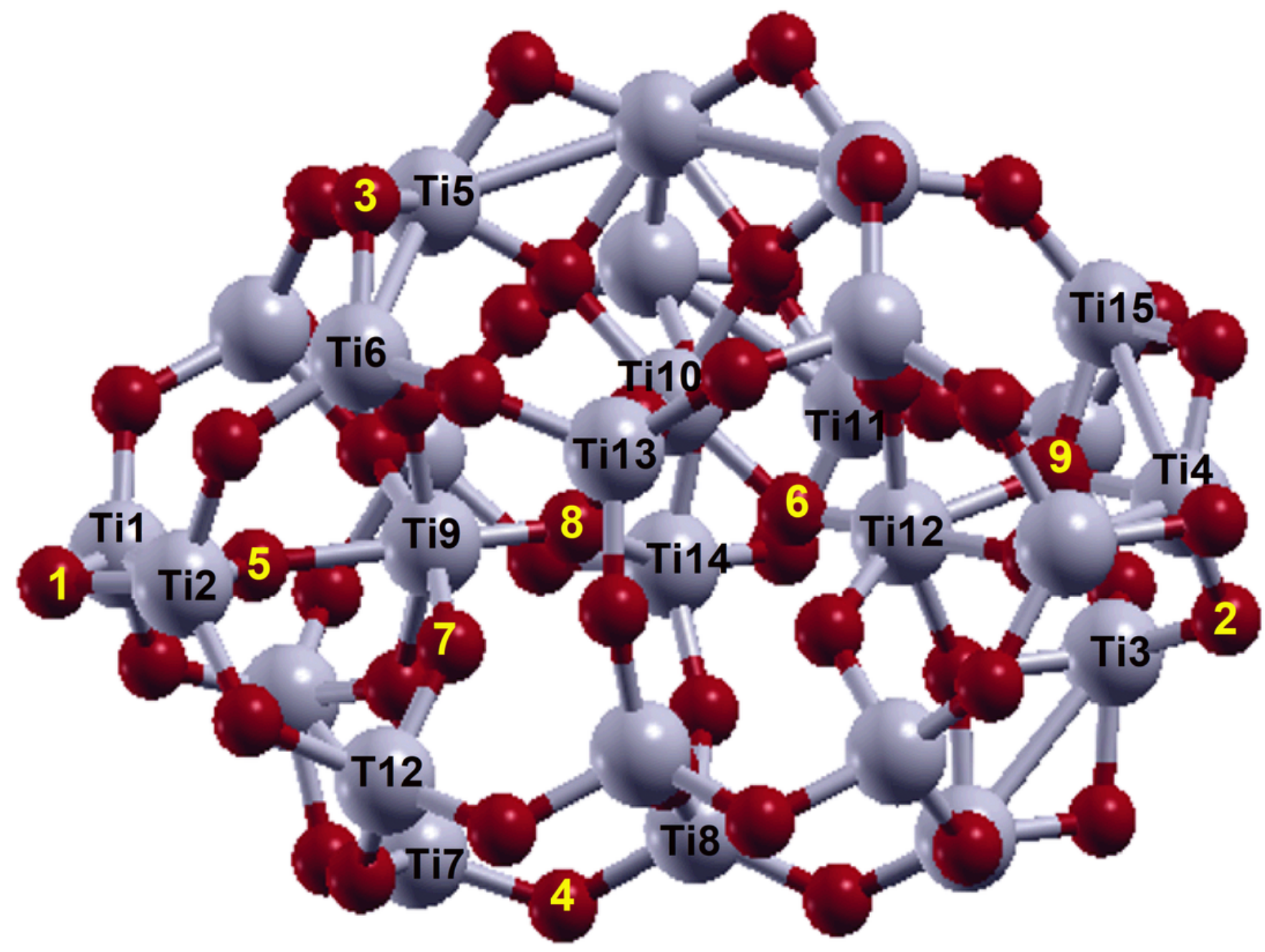

Figure 2

Labeling of Nitrogen substitutional positions for (Ti28055N1) cluster. 
a
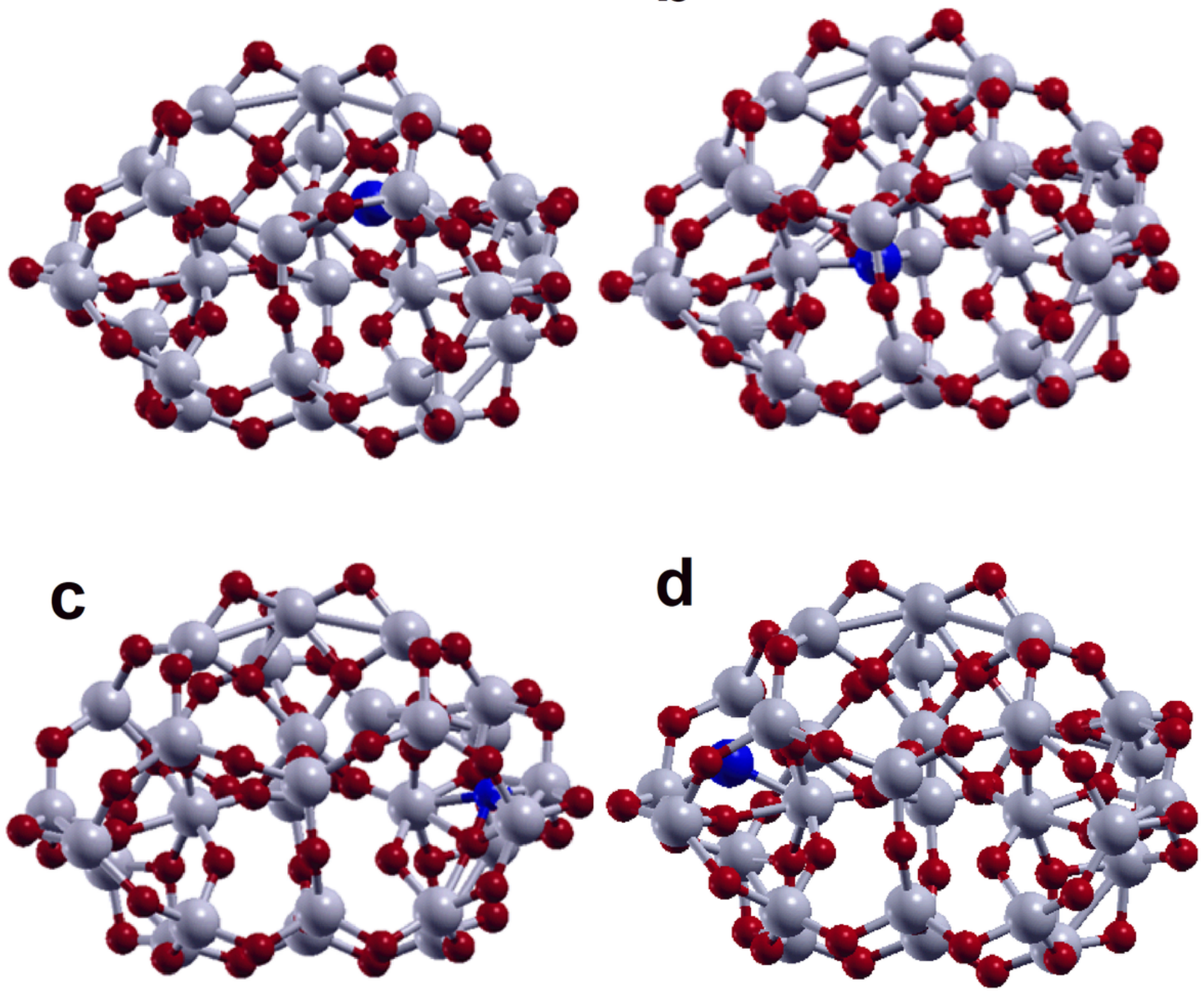

Figure 3

Optimized structure nitrogen atom at a different position for (Ti28056N1) cluster interstitial case, The gray (light) red (dark), blue balls correspond to $\mathrm{Ti} O$ and $\mathrm{N}$, respectively. 


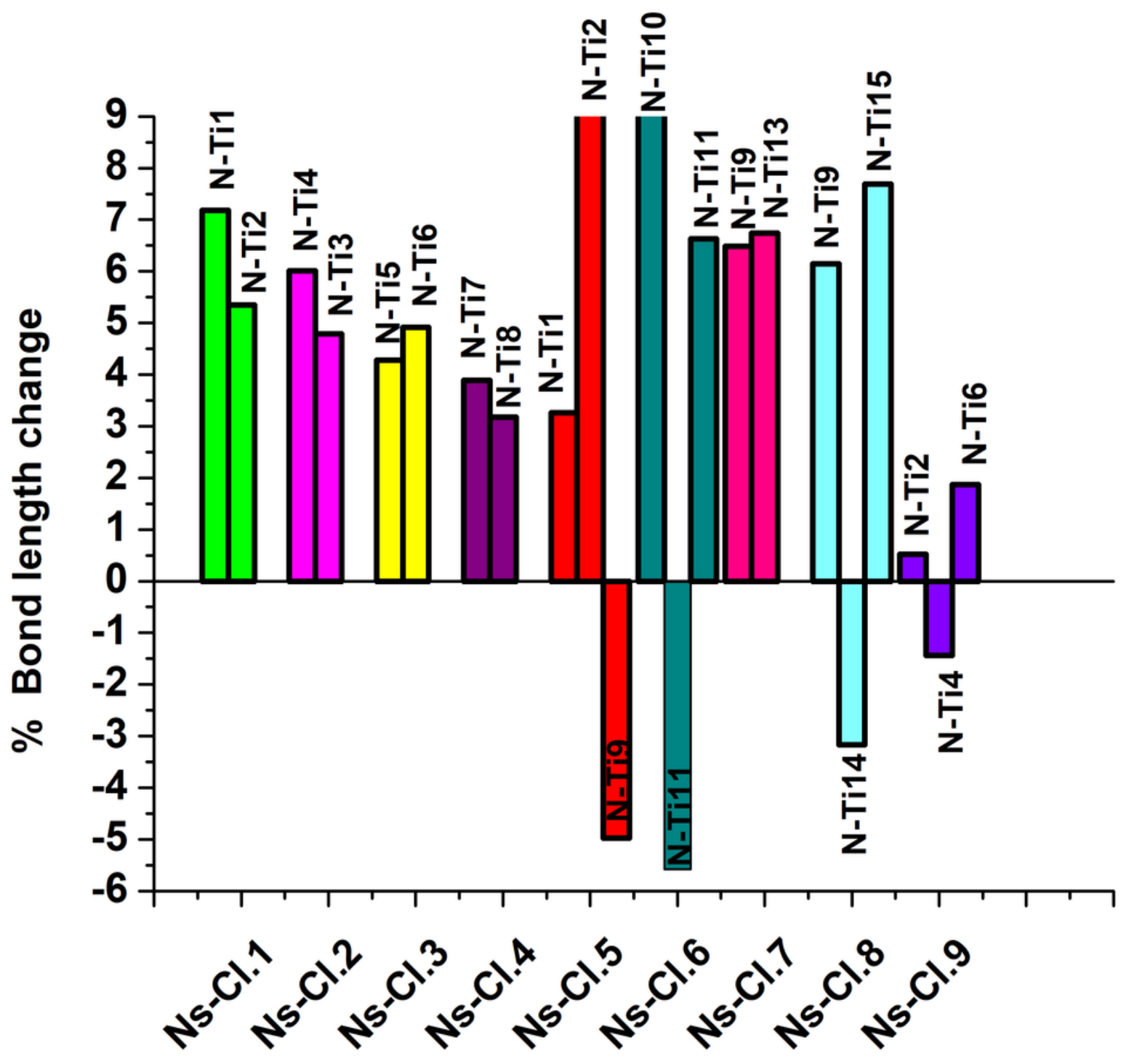

Figure 4

The percent fraction bond lengths of different substitutional positions of nitrogen dopants in titanium oxide (Ti28055N1) cluster. The bonds length around the $\mathrm{N}$ atom isidentified in Fig.2. 

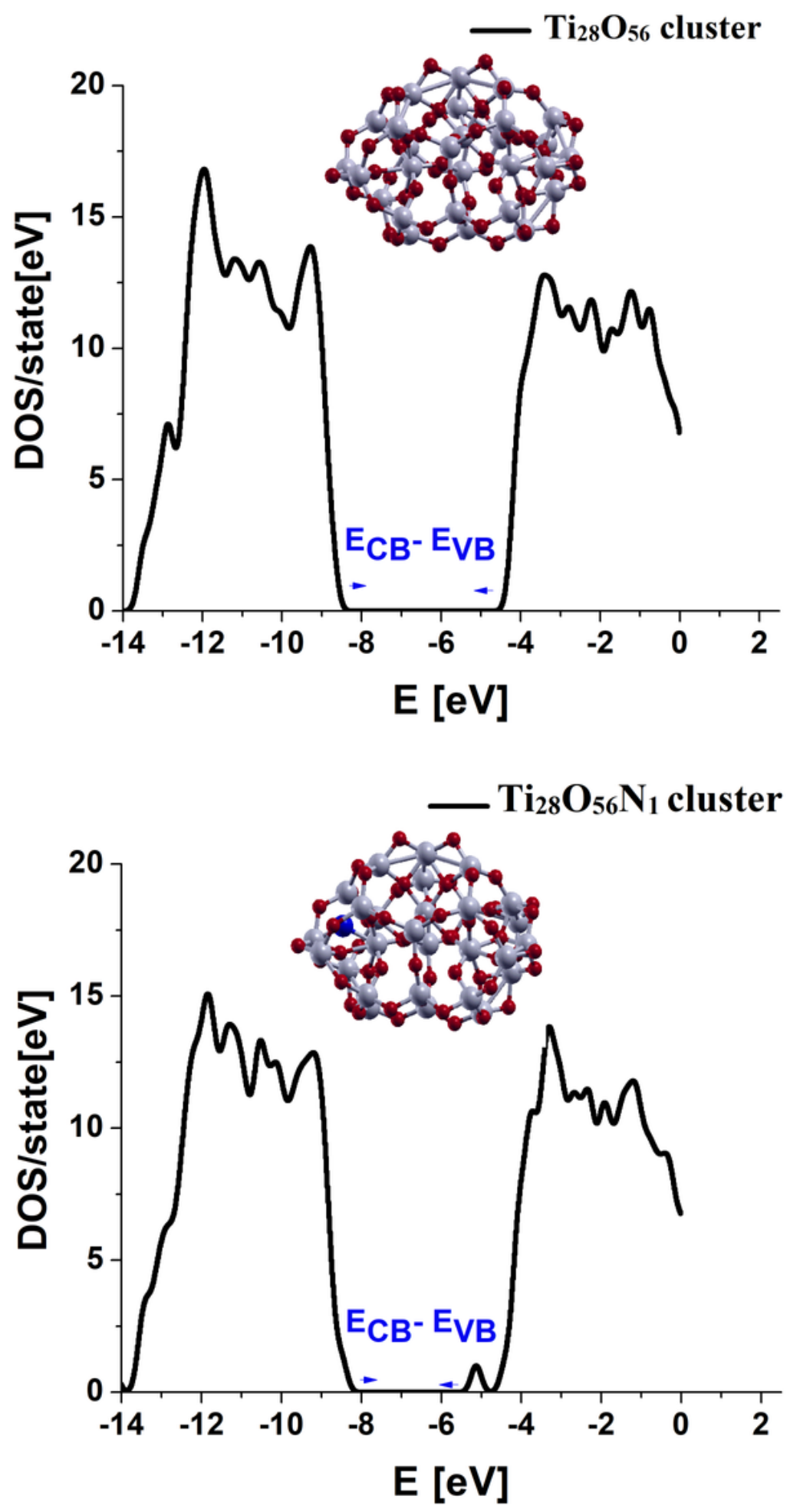

Figure 5

Density of state diagrams for (DOS) for pure (Ti28056) and Nitrogen doped (Ti28056 N1). Data were obtained from B3LYP/6-31G(d). 
a

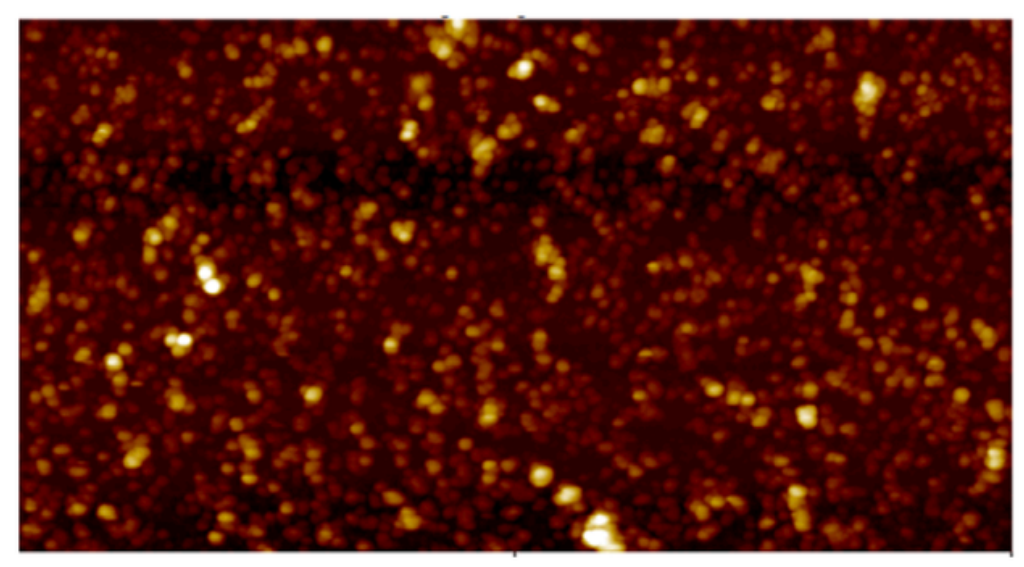

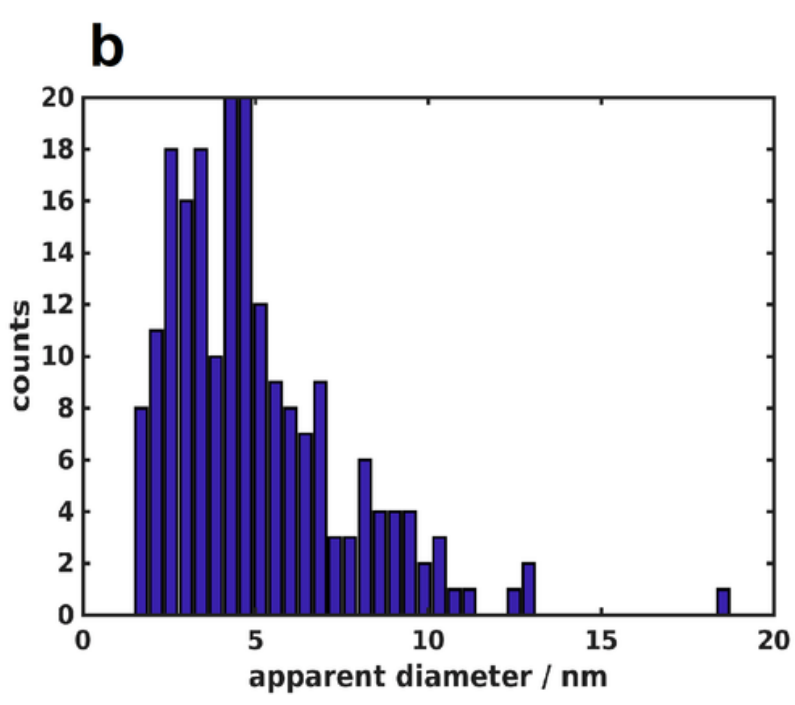

Figure 6

a: AFM image of the surface morphology of $\mathrm{N}$ doped TiO2 cluster film deposited on silicon,b: Histogram of particle size distribution

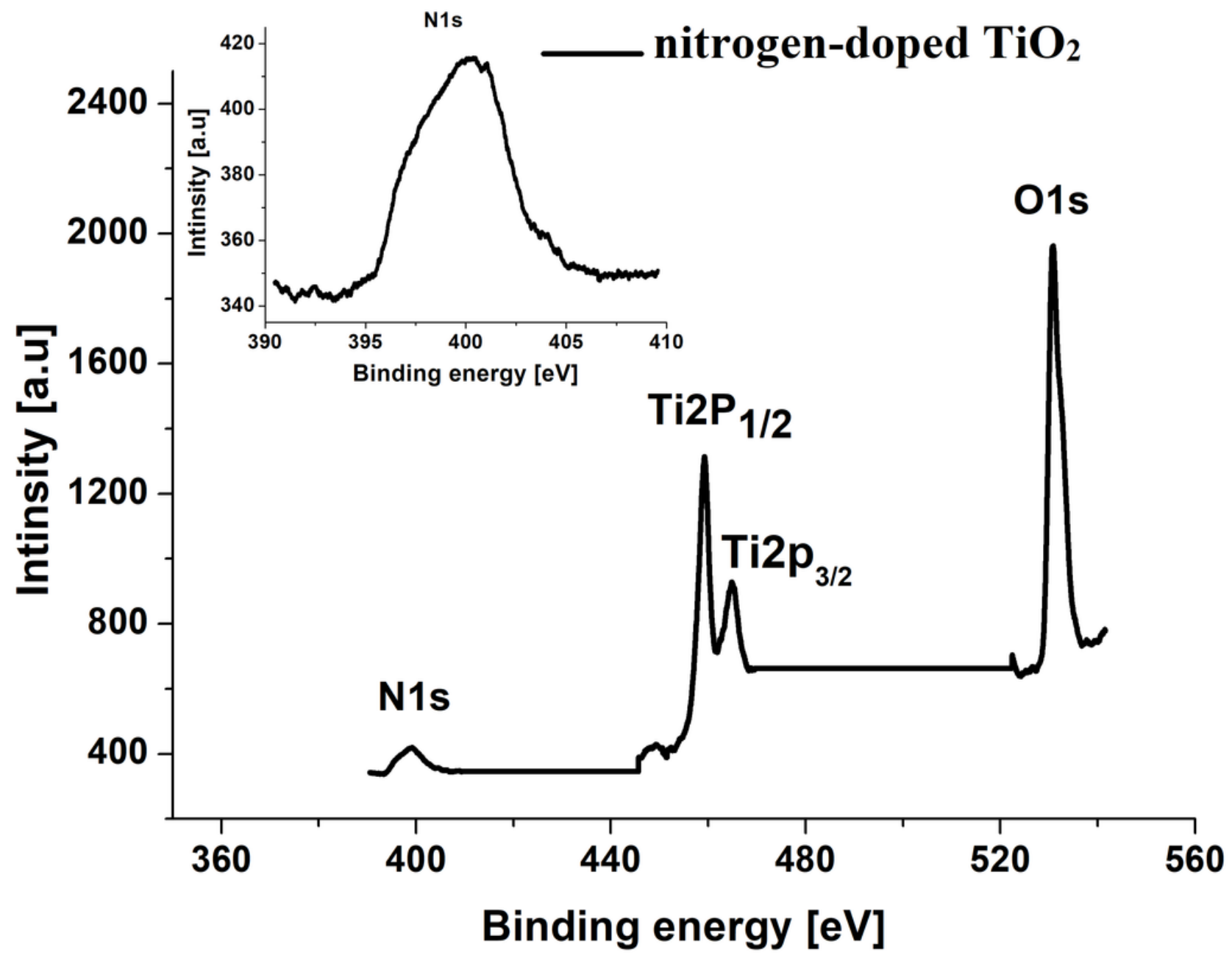

Figure 7 
XPS of Nitrogen doped TiO2 as generated, inset Fig. N1s peak centered at $400 \mathrm{eV}$ for N-TiO2.

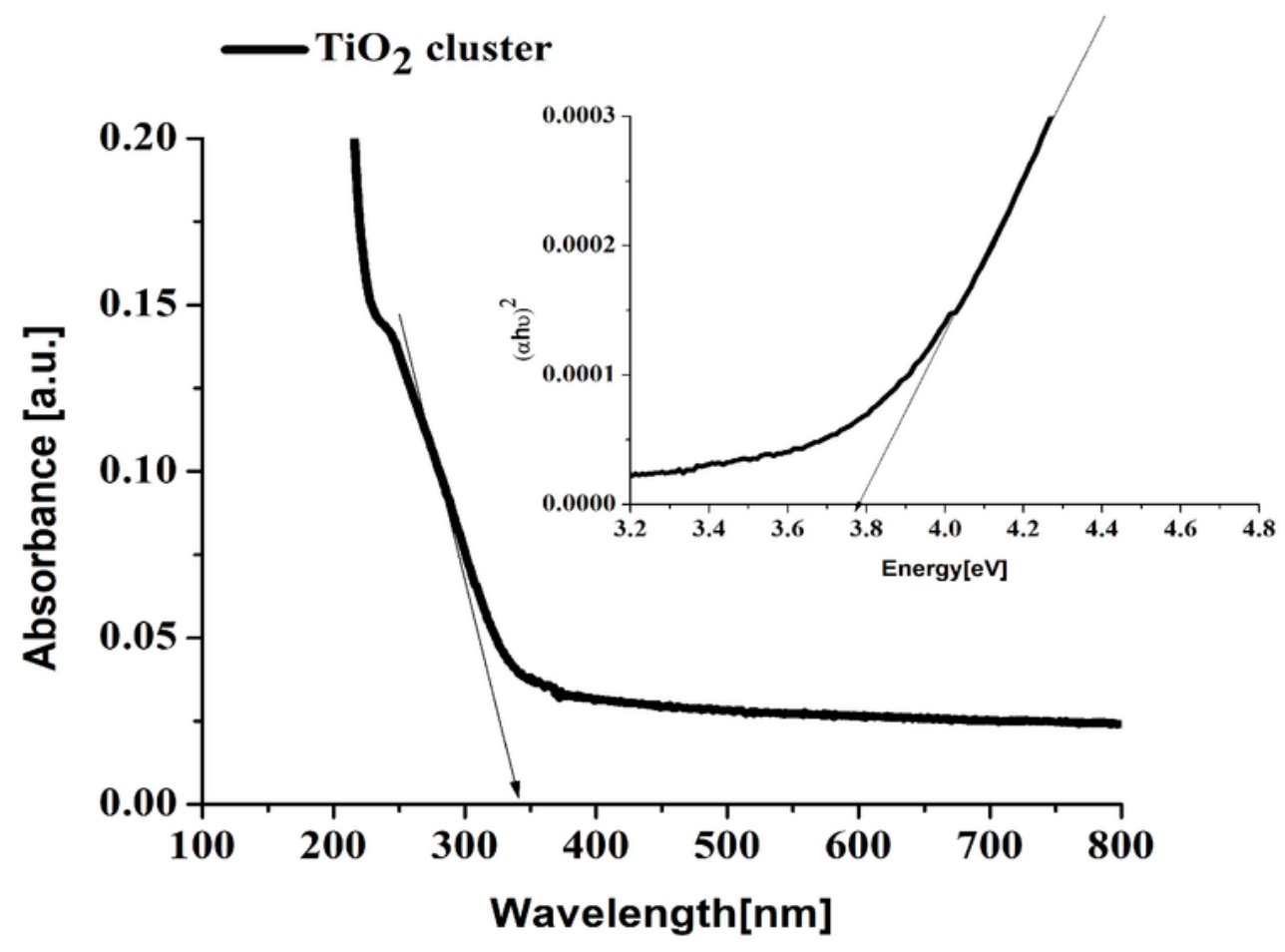

— nitrogen-doped $\mathrm{TiO}_{2}$ cluster

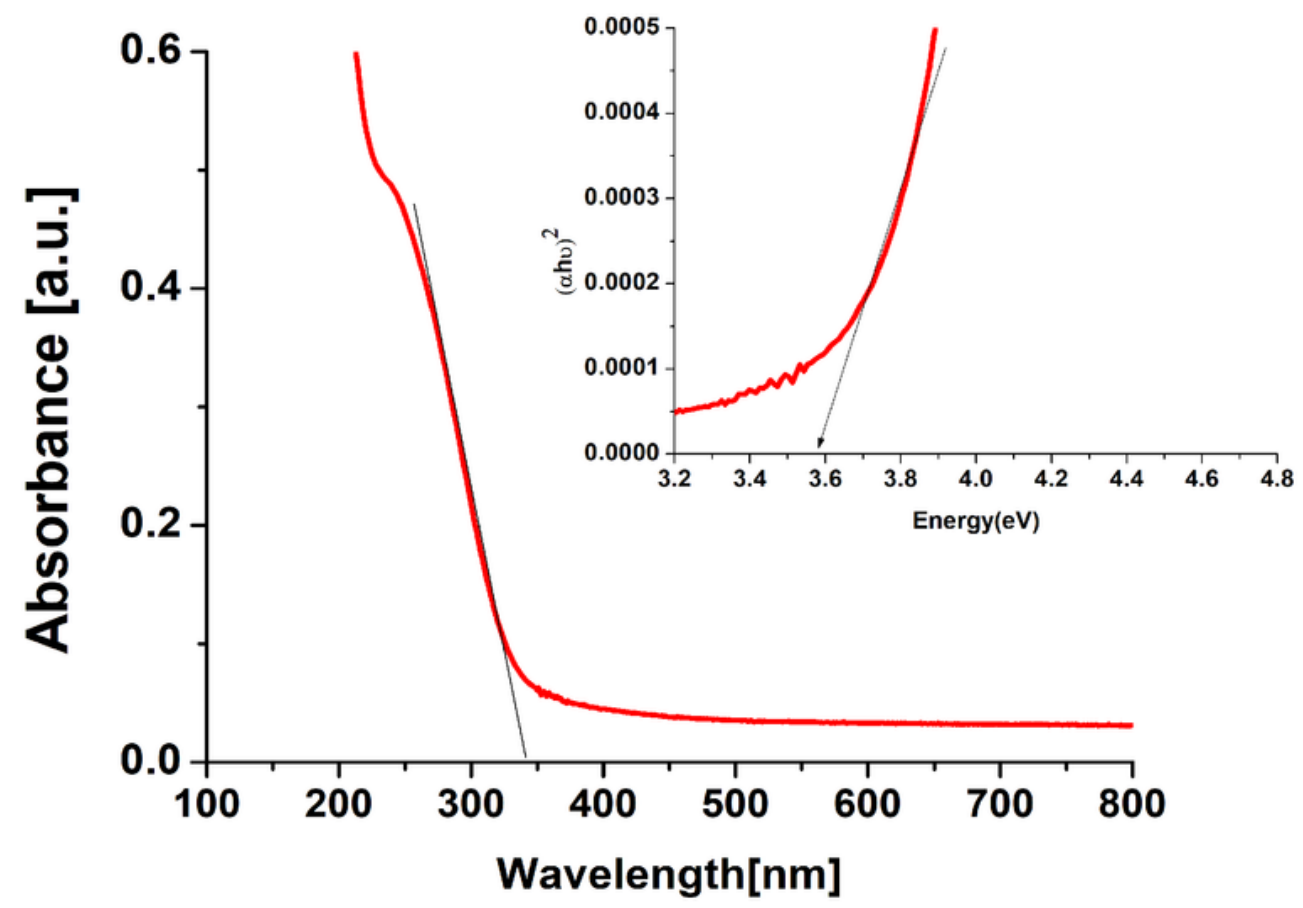

Figure 8

UV-vis spectra of pure and Nitrogen-doped (TiO2) nano structure insetFig. representsthe plots of (a.hv) 2 versus the energy level of the absorbed light. 


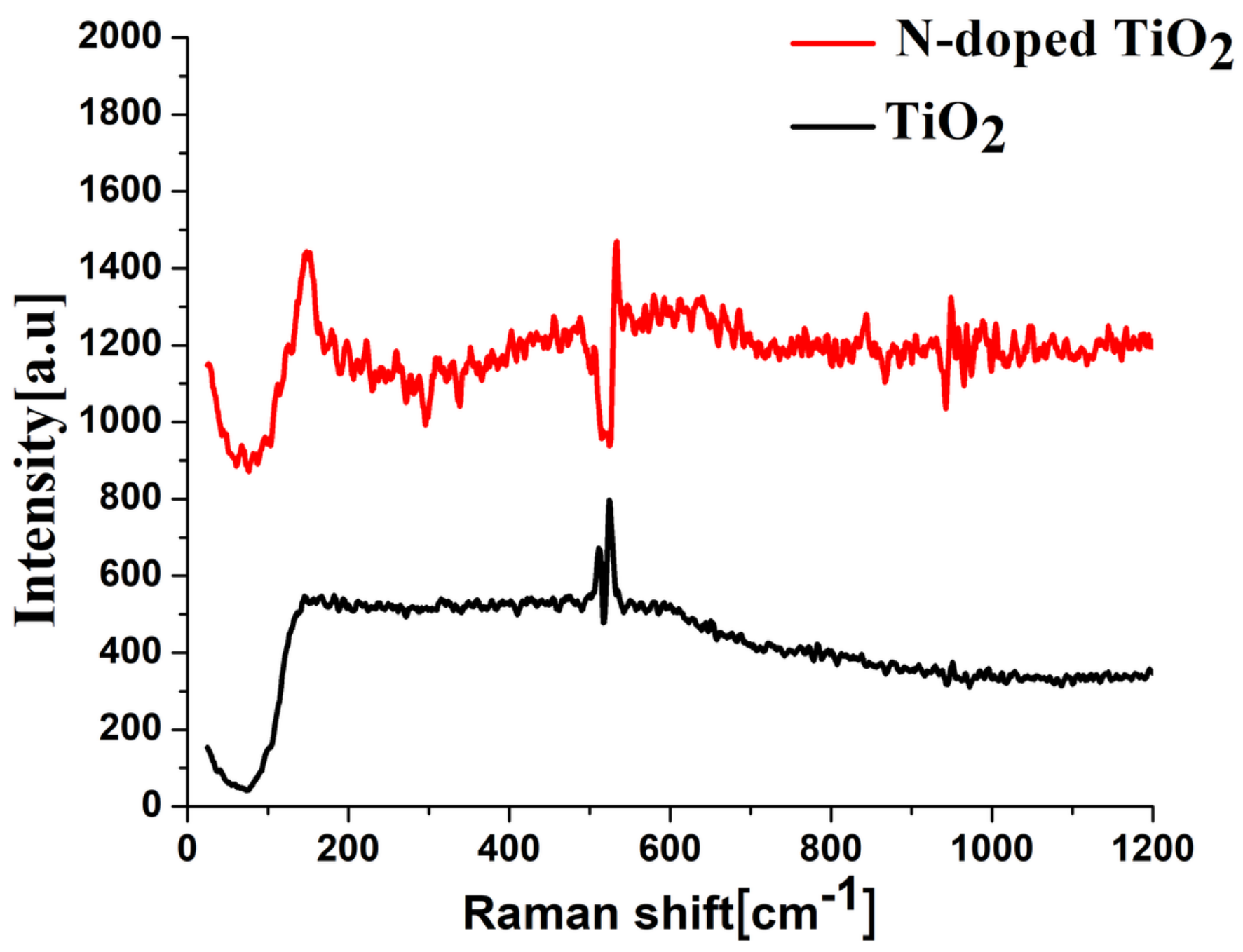

Figure 9

Raman spectra of pure and Nitrogen-doped (TiO2) nanocluster. 


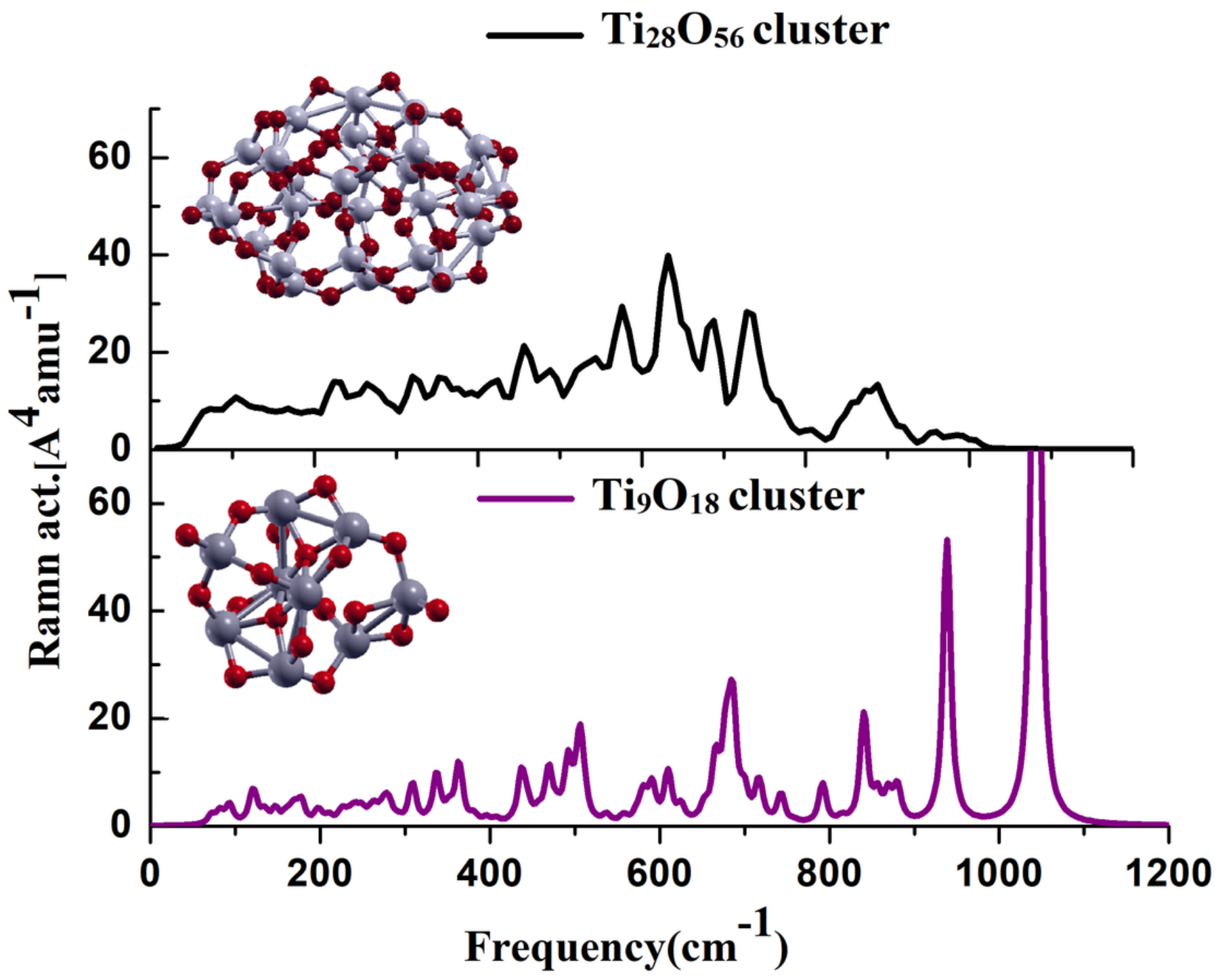

Figure 10

Raman activity of Ti9018, and Ti28056 calculated using Gaussian/ B3LYP/6-31G(d). 

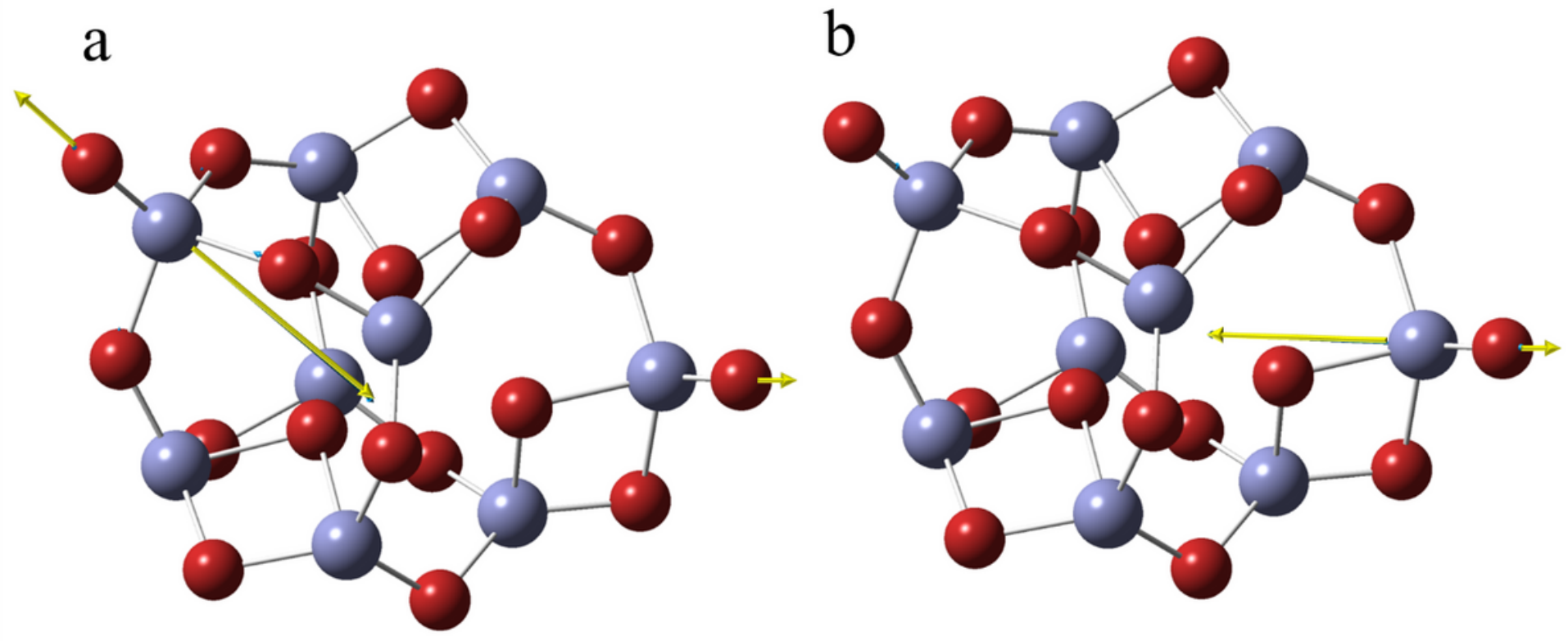

Figure 11

Mode of vibration (Ti9018) at $1040.92 \mathrm{~cm}-1$ and $1045.45 \mathrm{~cm}-1$ by Gaussian / B3LYP/6-31G(d). The gray (light) and red (dark) balls correspond to Ti and $\mathrm{O}$, respectively. 


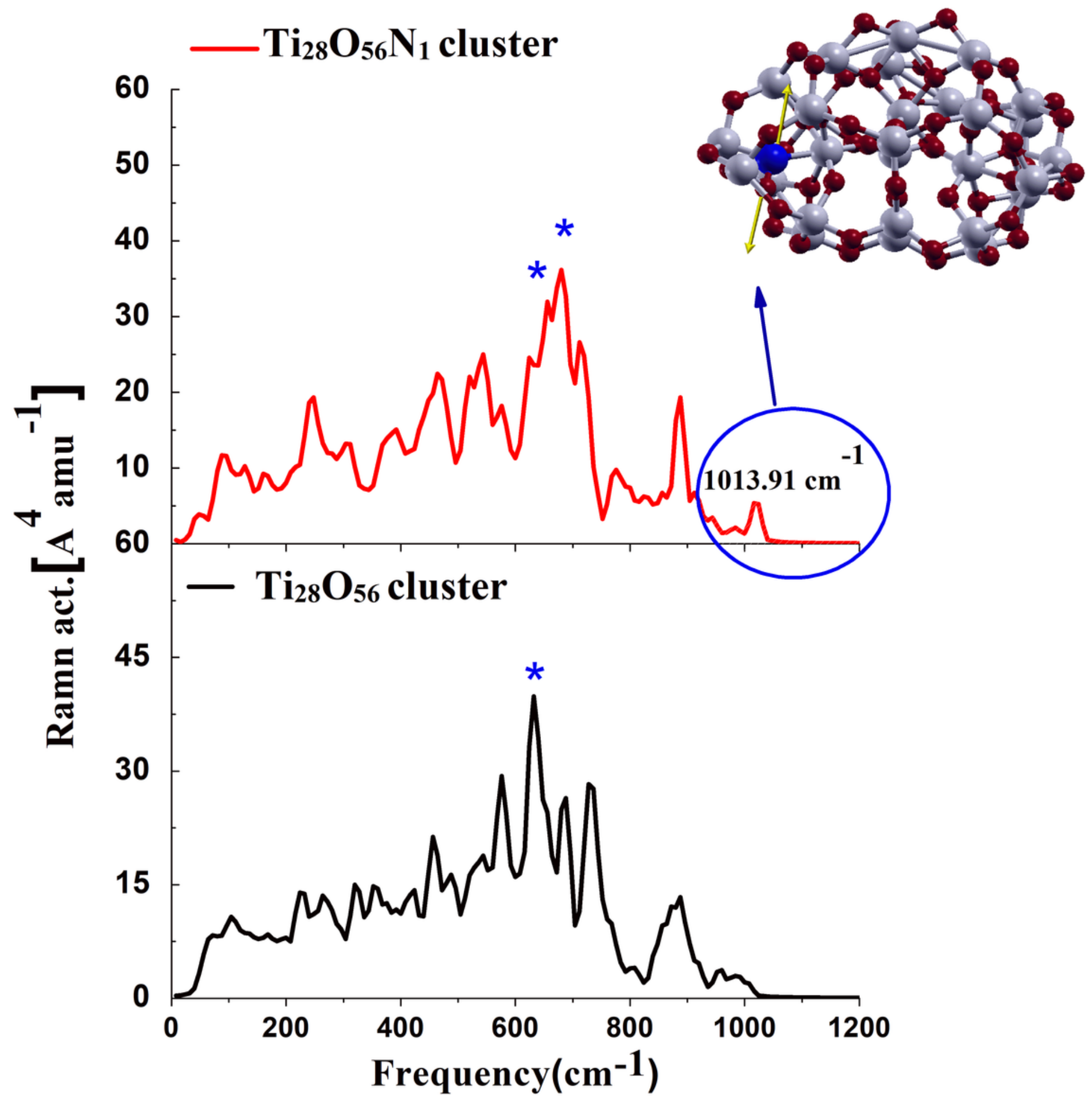

Figure 12

Raman spectral activities for pure (Ti28056) and Nitrogen-doped (Ti28056N1) nanoclusters using Gaussian/ B3LYP6/31G (d). The inset Fig. represents the vibrational mode of $\mathrm{N}-0$. The gray (light), red (dark), and blue balls correspond to $\mathrm{Ti}, \mathrm{O}$, and $\mathrm{N}$. 